CUPAUAM. 19-1992, 95-141

\title{
LA NECROPOLIS DE "LA CRUZ DEL NEGRO" (CARMONA, SEVILLA): EXCAVACIONES DE 1900 A 1905
}

\author{
JORGE MAIER
}

\section{Resumen}

En el presente artículo se presentan los resultados de las excavaciones efectuadas por D. Jorge Bonsor, entre 1900 y 1905, hasta ahora inéditos, recogidos en dos libretas de campo. Esta excepcional documentación nos permite valorar tanto el ritual funerario como la tipología de los enterramientos, así como constatar la presencia de sacrificios rituales en la necrópolis.

\section{Summary}

We do give in this paper the results of Mr. George Bonsor's excavations made between 1900 and 1905 , collected in two book notes, which had not been published until now.

This exceptional documentation let us fairly evaluate the funeral rites as much as the different kinds of burials, and also show evidence of ritual sacrifices at the necropolis.

\section{INTRODUCCION}

La Arqueología, prácticamente desde sus albores como disciplina científica en nuestro país, puso de manifiesto la importancia de Carmona como asentamiento humano desde muy antiguo. A ello contribuyó, muy intensamente, uno de los pioneros de la Arqueología en España, Don Jorge Bonsor.

Son muchos los yacimientos por él escavados, pero es nuestra la intención fijar la atención en una de las necrópolis tartésicas más importantes del Bajo Guadalquivir: la descubierta en la Cruz del Negro.

$\mathrm{Su}$ asociación a Carmona y su relación con otras necrópolis que la rodeaban, conformando un cinturón funerario alrededor de este estratégico enclave, como son las necrópolis tumulares de la Cañada de las Cabras, Alcantarilla, Campo de las Canteras, Huerta Nueva y Brenes, es un hecho comúnmente aceptado (Ruiz Delgado, 1986 a, 248-252).

El objetivo del presente trabajo es presentar los resultados de las excavaciones efectuadas por Jorge Bonsor entre los años 1900 y 1905, hasta ahora inéditos. Creemos que constituyen un 
documento excepcional para el conocimiento de la necrópolis, de la que si bien se conocen los materiales procedentes del yacimiento, se desconocen las circunstancias de los hallazgos. Estos nos permiten poder valorar el ritual funerario así como la tipología de los enterramientos.

\section{LA DOCUMENTACION}

Toda la documentación se encuentra recogida en dos pequeñas libretas de apuntes de campo manuscritas en francés y/o castellano: la libreta $\mathrm{n}^{\circ} 3(1900-1903)$ y la libreta $\mathrm{n}^{\circ} 5(1903-1905)$ (1). En ambas se describen muy detalladamente las circunstancias de los hallazgos de todas las tumbas excavadas por Bonsor o sus operarios así como las observaciones que Bonsor consideraba más relevantes. En la mayoría de los casos están acompañadas de un registro gráfico de la disposición de los ajuares o quemaderos, con un criterio bastante inusual en su época constituyendo un documento totalmente válido para la investigación arqueológica actual. En algunos casos, como veremos más adelante, y quizá debido a la regularidad de la disposición de las tumbas y de los ajuares, no es tan preciso como fuera de desear. En cualquier caso se conforma como un documento excepcional para el conocimiento del ritual funerario empleado en la necrópolis.

\section{DESCUBRIMIENTO E HISTORIA DE LAS INVESTIGACIONES}

Hace más de un siglo, con motivo del desmonte de terreno efectuado al construir la vía de ferrocarril que unía Carmona con Guadajoz, se descubrieron cerca del que fuera el ventorrillo de la Cruz del Negro, varias sepulturas de incineración que popularmente se conocían por carboneras. Estas constituían la que se conoce en la historiografía arqueológica como la necrópolis de la Cruz del Negro. Situada en una pequeña elevación natural a $1 \mathrm{~km}$ al noroeste de Carmona en dirección a Lora del Río, muy cerca del borde del alcor, quedó dividida en dos partes por la zanja que abrieron los constructores del ferrocarril. Fue en los taludes, en su parte más alta, a escasos metros de profundidad, donde, al parecer, se detectaron unas 15 o 20 tumbas que por supuesto fueron destruidas y los ajuares perdidos (Cañal, 1897, 352-353).

Como consecuencia de tales hechos y por el entusiasmo y curiosidad que despertaban los estudios prehistóricos, años más tarde, en 1895, se emprendió por parte de D. Rafael Pérez González, vecino de Carmona, la exploración del yacimiento practicando algunas excavaciones, principalmente en la zona de los taludes entre los que recogió al menos seis urnas completas, fragmentos de broche de cinturón, fíbulas, agujas y varias puntas de flecha. También excavó alguna tumba D. José Vega, miembro de la Sociedad Arqueológica de Carmona. Es Carlos Cañal $(1897,353-360)$ quien nos refiere estas primeras noticias, y da a conocer la descripción del tipo de enterramiento y los diversos materiales que componían los ajuares, fruto de las excavaciones de D. Rafael Pérez González, su primer descubridor.

Es sin embargo a D. Jorge Bonsor a quien debemos la mayor parte de los datos y los materiales conocidos de la necrópolis. Este intentó, también, excavar en la zona de los taludes, pero el propietario del terreno, ante las numerosas acciones clandestinas que venían produciéndose, no le permitió realizar ningún trabajo en esa zona, por lo que hubo de trasladarse a otros puntos cerca-

(1) Estas se encuentran depositadas hoy en día en el Archivo General de Andalucía, a cuya directora, Ester Cruces expreso mi más sincero agradecimiento así como a José Manuel Rodríguez Hidalgo, Arqueólogo Provincial de Sevilla. 
nos. Su actividad en la necrópolis comenzó en la primavera de 1898 aunque sabemos que adquirió dos peines de marfil enteros grabados, algunas cuentas de oro, fragmentos de marfil quemados, un hacha de piedra negra y dos urnas cinerarias, en 1896, a su operario Rafael Pérez Barrera. Los resultados de esta campaña de excavación junto con varios materiales más, adquiridos hasta 1899 , fueron publicados en su obra más significativa y que continúa siendo referencia fundamental para el estudio el yacimiento: "Les Colonies agricoles preromaines de la valleé du Betis".

Con posterioridad a esta fecha Bonsor realizó intermitentemente, por lo menos hasta 1911, varias campañas de excavaciones en el yacimiento. Los trabajos más continuados se llevaron a cabo entre los años 1900 y 1905, los que son objeto del presente artículo.

De todos estos años de trabajo Bonsor no publicó prácticamente nada, a excepción de un enterramiento de una mujer y un niño y una estela (Bonsor, 1927, 292-295). En 1928 dio a conocer en un estudio monográfico los marfiles grabados fenicios procedentes de los Alcores, entre los que evidentemente figuraban los recogidos en la Cruz del Negro (Bonsor, 1928, 53105).

Gran parte de los materiales de estas campañas fueron adquiridos por la Hispanic Society de Nueva York en los años 1905, 1906 y 1908 donde se encuentran depositados actualmente. Otro gran lote de estos se halla en la colección que se conserva en el Castillo de Mairena del Arcor, en la que era residencia y museo de Jorge Bonsor.

Recientemente, entre los meses de enero y julio de 1990, se ha reexcavado la necrópolis en trabajos de urgencia cuyos resultados se encuentran aún en proceso de estudio (Gil de los Reyes $y$ otros, en prensa).

Sin embargo los materiales procedentes del yacimiento han venido siendo objeto de varios estudios parciales, sobre todo en los dos últimas décadas, en los que el interés por la protohistoria del Bajo Guadalquivir ha ido paulatinamente en aumento. L. Monteagudo (1953, 356-370) publicó una serie de dibujos realizados por Bonsor que iban destinados a la confección de un álbum arqueológico de los Alcores, en el que se recogen varias sepulturas y materiales. Estas sepulturas cuyos dibujos originales se conservan en el Castillo de Mairena del Alcor están también recogidos como bocetos en la documentación que presentamos.

La investigación moderna ha aportado estudios monográficos de los ajuares de la necrópolis como son las fíbulas (Shüle, 1961, 339-375; Cuadrado, 1963, 7-61; Ruiz Delgado, 1986b, 501; Storch, 1989), los broches de cinturón (Cuadrado y Brito, 1970, 494-514; Cerdeńo, 1981, 3156), la cerámica a torno (Aubet, 1976-78, 267-287), la cerámica pintada a mano (Aubet, 1982, 385-388; Jiménez, 1986, 477-489), la cerámica pintada figurada (Remesal, 1979, 3-21) y los marfiles fenicios grabados (Aubet, 1979, 5-67) que sin duda han precisado el carácter y la cronología de esta importante necrópolis tartésica.

\section{UNIDADES DE ENTERRAMIENTO}

El orden de numeración de las sepulturas descritas corresponde a la fecha de descubrimiento y se indica la numeración de las hojas de la libreta en que se encuentra.

No 1. 15-2-1900. 7 L.3, $7 V^{\circ}$ L.3.

Bonsor nos describe en un dibujo muy detalladamente la disposición del ajuar entorno a un quemadero. Hay que advertir que Bonsor emplea la designación de crátera al referirse a la forma conocida como vaso chardon a mano y urna en el caso de urnas globulares a torno. 
Se trata de una fosa de cremación o quemadero de sección escalonada de $1.60 \mathrm{~m}$ de largo por $0.95 \mathrm{~m}$ de ancho que se halló a $1.50 \mathrm{~m}$ de profundidad. Esta presenta una fosa central, más estrecha $10 \mathrm{~cm}$ más profunda. Bonsor observa mucha cantidad de carbón por lo que supone que habría sido cubierta de tierra antes de producirse la combustión completa.

Este es el único caso en que el ajuar se distribuye alrededor de la fosa de cremación, al norte en el exterior y al sur en su interior depositados directamente sobre el suelo, además de cuatro lucernas situadas en el primer escalón de los cuatro lados del rectángulo que configura la fosa.

A) En el exterior:

1. Vaso chardon tumbado que Bonsor describe como de cerámica primitiva de tierra marrón micácea que contenía restos de madera carbonizada.

2. Un plato, debajo del vaso anterior.

3 . Vaso chardon de pie junto a estos.

4. Urna globular a torno con dos asas que contenía las cenizas humanas y diversos objetos de marfil grabados y quemados.

B) En el interior:

5. Gran plato negro con pie.

6. Un plato en una gran fuente con pie.

7. Cuatro lucernas, tres de un mechero y una de dos, orientados estos hacia la parte central del quemadero.

8. Fragmentos de barro cocido que Bonsor asocia con un soporte de un vaso.

No 2. 27-2-1900. 12Vo L.3.

Esta tumba y la siguiente se encontraron superpuestas pero con orientaciones sensiblemente diferentes. Ambas se describen en el mismo dibujo con la orientación de ambas fosas y la situación de los hoyos de deposición. En la primera de ellas se observa una fosa de cremación de sección escalonada. Al Este, en su interior se encontraron numerosos fragmentos de marfil quemado que Bonsor atribuye a algún tipo de mueble.

En la cabecera Oeste y afectando parcialmente a ésta se encontraba el hoyo de deposición, de planta circular, que contenía los restos de madera carbonizada de la pira e imbuidos entre ellos se hallaban una urna pequeña, un vaso y un plato de los que Bonsor no especifica nada.

No3. 27-2-1900. 11 L.3. 11Vo L.3.

Por debajo de ésta $(20 \mathrm{~cm})$ se hallaba la segunda con orientación S.O. N.E. y no fue afectada al construir la tumba superior.

Bonsor la describe más detalladamente en un segundo dibujo pues es la primera inhumación que se halló en la Cruz del Negro. Se observa una fosa regular en la que está depositado un individuo con la cara vuelta hacia el lado izquierdo. El cuerpo estaba tendido de cara al suelo y la cabeza descansa sobre el lado izquierdo y las manos sobre el vientre. Medía $1.58 \mathrm{~m}$ de largo. Por la anchura de la cadera $(0.30 \mathrm{~cm}$.) Bonsor indica que correspondería a un individuo femenino. También nos dice que el suelo de la sepultura, lo mismo que las paredes, están recubiertas de tierra gredosa quemada. Así mismo observa que en la tierra alrededor del cuerpo se encontraron residuos de carbón de madera.

El hoyo de deposición estaba situado junto a el extremo N.E. de la fosa y contenía un vaso chardon y un plato. 


\section{No 4 12-3-1900 12Vo L.3.}

Se describe en un dibujo en planta una fosa con un individuo adulto y junto a ésta un hoyo de deposición de planta circular. La fosa posee una orientación S.O. N.E. con la cabeza del individuo al S.O.. El cuerpo yace con el cráneo cara al cielo y una piedra caliza sobre él y las manos recogidas sobre el vientre. En las anotaciones Bonsor dice que las paredes de la fosa están quemadas y en la tierra que recubría el cuerpo se hallaron carbones de madera esparcidos y cenizas.

En el hoyo de deposición, situado a la altura de la cadera y junto a la fosa, se halló un vaso chardon introducido entre los restos de la pira que debería de contener los huesos humanos incinerados.

\section{No 5. 9-4-1900. 15 L.3}

Bonsor describe esta tumba en un dibujo en sección. En éste se observa un corte escalonado en la tierra roja, que es donde se realizan todas las estructuras funerarias, como se ha comprobado en las recientes excavaciones (Gil de los Reyes y otros, en prensa). En su parte central presenta una pequeña fosa rectangular de 0.33 de largo por 0.21 de ancho y $10 \mathrm{~cm}$. de profundidad. La fosa contenía en un pequeño agujero los restos humanos incinerados y un fragmento de urna pintada. Todo el conjunto se encontró cubierto de grandes piedras a una profundidad de $70 \mathrm{~cm}$ desde la superficie del terreno constituyendo uno de los pocos ejemplos de sistemas de cubrición de los enterramientos.

\section{No 6. 3-1-1901. 14 L.3.}

Otro caso como el anterior en que Bonsor nos describe la tumba en un dibujo en sección y en planta. En la sección se aprecia la estratigrafía de la necrópolis en la que refleja los tipos de tierra y las profundidades a las que se produjeron los hallazgos. A $1.20 \mathrm{~m}$ de profundidad se halló en la tierra roja endurecida. Por debajo de ésta una tierra de cantos y arcilla quemada en la superficie y algunos carbones de madera. Junto a ésta el hoyo de deposición con un vaso de chardon, con la boca a la altura de la superficie quemada y en su interior los huesos calcinados y restos de conchas. En el dibujo en planta Bonsor añade junto al vaso chardon la presencia de un cráneo de un niño, que parece que fue lo único que se pudo recuperar.

Según las anotaciones Bonsor dice que la pira fue construida directamente sobre el suelo, lo cual supone una excepción en la necrópolis.

\section{No 7. 15-1-1901. 16 L.3.}

Las unidades de enterramiento siguientes hasta la $\mathrm{n}^{\circ} 12$ inclusive se describen en un mismo plano (16 L.3). Se trata de un plano muy esquemático donde ha situado los puntos donde fueron hallados los enterramientos y en los que anota las distancias entre éstos y dos árboles (olivos) que tomó como referencia para calcular una posible relación espacial entre las diversas tumbas. Son descripciones muy someras e imprecisas acompañadas por algunas anotaciones. Hemos seguido la correlación empleada por Bonsor en el plano. Según sus anotaciones todas ellas se encontraban a $1.12 \mathrm{~m}$ de profundidad desde el nivel más superficial hasta el lugar de deposición.

Correspondiente a la letra A del plano, se halló, sin más especificaciones, una pequeña urna con dos asas que contenía los huesos humanos incinerados y un pequeño alabastrón fenicio del que hace un dibujo. 
No 8. 15-1-1901. 15Vo L.3, 16 L.3.

Corresponde a las letras $\mathrm{B}$ y $\mathrm{C}$ del plano, que en realidad constituyen un único enterramiento según se desprende del dibujo del plano y las anotaciones. Según esta última B corresponde a un quemadero en el que se encontró mucha cantidad de madera de olivo carbonizada. En medio del quemadero se halló depositado un vaso chardon que contenía un fragmento de una caja de marfil y más fragmentos entre los carbones alrededor de él. También se halló, entre los carbones entorno a éste fragmentos de un pequeño vaso de dos asas. Fuera del quemadero, al borde del mismo en el Oeste, se encontraba depositada una urna globular $\mathrm{C}$ con la incineración y fue afectada por el fuego en su parte próxima a éste. Del otro lado, la urna linda con una especie de plataforma de una tierra amarillenta, ésta se encontraba a $0.50 \mathrm{~m}$ por debajo del nivel arado.

\section{No 9. 15-1-1901. 15Vo L.3, 16 L.3.}

Se corresponde con la letras $\mathrm{D}$ y E del plano. En las anotaciones $\mathrm{D}$ lo compone un vaso chardon cubierto con una fuente. E corresponde a una urna globular que contenía un broche de cinturón. A continuación nos dice que del lado del fuego (suponemos que se refiere al quemadero) estaban depositadas algunas piedras blancas para proteger la urna. Ambos vasos se distanciaban medio metro. Es de suponer que la urna contenía los restos incinerados y el vaso chardon, como en otros casos, ser un vaso de ofrendas.

\section{No 10. 15-1-1901. 16 L.3, 16Vo L.3.}

Se trata de un quemadero del que no refleja su tipología, dimensiones u orientación. Este presentaba en el centro, el hoyo de deposición, que albergaba los huesos incinerados, sin urna, y dos objetos de bronce que dibuja. Estos parecen ser unas varillas cuyos extremos están rematados por una de flor abierta de cuatro pétalos. Sabemos que estos son de bronce por ejemplares análogos que se conservan en el Castillo de Mairena del Alcor.

No 11. 15-1-1901. 16 L.3, 16Vo L.3.

Con la letra $\mathrm{G}$ Bonsor nos describe el hallazgo de un vaso chardon y fragmentos de un broche de cinturón en su interior.

Especifica que la urna no se ha encontrado, por lo que suponemos que el vaso chardon no contenía la incineración. No dice nada sobre la existencia del quemadero, sin embargo en el plano indica la orientación S.O. N.E. que sin duda corresponde al quemadero. Siendo así el vaso chardon estaría situado en el centro del quemadero o al menos en su interior, lo que parece una constante en este grupo de enterramientos como afirma Bonsor en sus anotaciones diciendo que la urna se halla generalmente en el centro del quemadero. Observa que se encuentran muchos restos de huesos entre las cenizas de la pira "ya que no se preocupaban mucho de recogerlos puesto que la urna iba a ser depositada en el mismo lugar".

No 12. 15-1-1901. 16 L.3, 16Vo L.3.

El último enterramiento de este grupo corresponde a la letra $\mathrm{H}$. Bonsor dice que halló una urna a $90 \mathrm{~cm}$ de profundidad, no especificando nada más. Sólo contenía los huesos incinerados. Añade también que la orientación del quemadero es, como en la mayor parte de los casos descritos N.E. S.O. pero no describe su tipología ni la situación de la urna respecto a éste. 
No 13. 29-1 1901. 18 L.3.

Bonsor nos dice que a $1.30 \mathrm{~m}$ de profundidad halló un quemadero que presentaba en el centro mismo el hoyo de deposición conteniendo un vaso chardon, del que dibuja el perfil, que presentó en su interior tierra, guijarros y restos de cerámica. Junto a este se hallaron dos fragmentos de cerámica de pasta negruzca que dibuja y en el que se aprecia que está decorada con incisiones y posee un mamelón. Continúa la descripción señalando que al lado del vaso chardon, en el suelo, se hallaban depositados los huesos humanos incinerados, cubiertos por una pátera de cerámica negra muy fina.

Por otra parte resalta Bonsor en sus anotaciones que parece indispensable la presencia del vaso chardon en los enterramientos de la Cruz del Negro.

No 14. 5-2-1901. 17 L.3, 18Vo L.3, 19 L.3, $19^{\circ}$ Vo L.3.

Este es el único enterramiento que publicó Bonsor de todas las campañas de excavación posteriores a 1899 (Bonsor, 1927, fig. 5). Se describe muy detalladamente en un dibujo en planta un individuo adulto y otro infantil inhumados a escasa distancia uno del otro. Cada una de las inhumaciones posee una urna depositada junto a ellos con los huesos incinerados. Por este motivo los hemos considerado como dos unidades de enterramiento individualizadas.

La inhumación infantil estaba recostada sobre el lado derecho. En este mismo lado y a la altura de la cabeza se halló una cuenta de vidrio. Junto al cráneo, que parece haber sido aplastado intencionadamente, según Bonsor, se depositó un vaso a mano sin asas de cerámica parda muy friable con los huesos incinerados y un anillo de cobre.

No 15. 5-2-1901. 17 L.3, 19 L.3, 19Vo L.3.

El segundo enterramiento descrito, como se aprecia en el dibujo, es una inhumación de un adulto recostado, con las piernas ligeramente flexionadas sobre su lado izquierdo y el brazo derecho recogido sobre el pecho. Según Bonsor los dientes estaban en muy buen estado pero sin embargo el cráneo había sido aplastado intencionadamente. Las suturas, continúa Bonsor, estaban casi cerradas a pesar de haber sido aplastado y no es precisamente en estas donde se encontró fragmentado. La dimensión del cuerpo le hace pensar al arqueólogo inglés que se trate de una mujer.

En el dibujo se observa que tiene depositada a la altura del brazo derecho una lucerna fenicia de un mechero y dos fragmentos de asa de ánfora. Uno de ellos lo tenía, según nos dice Bonsor, bajo el vientre intencionadamente y el otro a la altura de la tibia. Por último se recogió un trozo de lápiz de ocre amarillo detrás del cráneo.

La urna se depositó junto a los pies del individuo. Es una urna globular pintada a bandas rojas según las anotaciones. No contenía más que los huesos humanos incinerados. Ambas tumbas se hallaron a dos metros de distancia del enterramiento $\mathrm{n}^{\circ} 3$.

Para Bonsor, como se lee en sus anotaciones, se trata claramente de una mujer y su hijo. Dice que los dos cráneos estaban totalmente aplastados y que esto no tiene nada que ver con el peso de la tierra. A continuación se refiere a la existencia de una fosa que contenía los cuerpos pero que en el dibujo no se refleja. De ésta dice que el fondo de la misma es excesivamente duro y se trata de la grava natural sobre la cual se habría echado una fina capa de tierra muy roja. Continua diciendo,"en estas sepulturas (inhumaciones) se recubre el cuerpo de tierra después de depositarlo en la fosa, encendiéndose posteriormente un fuergo con ramas. Las dos urnas se colocaron en la grava al mismo nivel que el cuerpo. Dichas incineraciones son contemporáneas 
pues de los esqueletos. Esto, por otra parte, quedaría confirmado por la capa de tierra arcillosa de color amarillento que lo cubre todo".

No 16. 8-2-1901. 17Vo L.3.

Bonsor describe casi telegráficamente este enterramiento. Nos habla de un hoyo de deposición lleno de carbón con dos urnas y un vaso chardon. Ambas urnas contenían un broche de cinturón cada una. No se especifica nada sobre el quemadero.

\section{No 17. 9-2-1901. 17Vo L.3.}

Otro caso en el que Bonsor es muy impreciso en sus descripciones. Dice que en un hoyo de deposición se halló un vaso chardon. Al lado un plato cubriendo los huesos humados incinerados depositados en el suelo. Entre estos se halló una placa de broche de cinturón.

No 18. 5-3-1901. 20 L.3.

Se describe un hoyo de deposición con un vaso chardon que dibuja. Alrededor de éste se encontraban las cenizas del quemadero y los huesos humanos incinerados y entre estos una fíbula de doble resorte que dibuja. Junto a ésta se hallaron así mismo una punta de lanza y su talón que, según él, estaban depositadas de forma intencionada y afectados por el fuego, además de un cuchillito de hierro y una especie de pulsera de bronce que dibuja.

No 19. 28-3-1901. 20Vo L.3.

Bonsor nos dice que ha asistido personalmente al hallazgo de una urna situada al Oeste de una vaso chardon. La boca de la urna se hallaba a $0.60 \mathrm{~m}$ del nivel del suelo arado. En la urna, que él mismo vació, encontró los huesos humanos incinerados y un peine de marfil grabado por ambas caras con un león alzando una pata, siendo el único peine de marfil que posee contexto definitivo (Bonsor, 1928, 57, lám. XXIII; Aubet, 1979, 20, fig. 1 nº $^{\circ}$ ). No especifica nada sobre el quemadero y sobre la situación del hoyo de deposición respecto a éste. Sin embargo Bonsor en sus anotaciones dice que la urna se halla generalmente situada al Oeste del vaso chardon.

No 20. 29-3-1901. 21 L.3.

En este caso se describe el hallazgo de una vaso chardon con platos y fuentes rotos en su interior y una gran fuente a modo de cubierta. Los huesos humanos se hallaron depositados en el suelo junto al vaso chardon y cubiertos por una fuente. Entre ellos se encontró un anillo y otros fragmentos sin especificar, de cobre.

Por otra parte Bonsor anota que entre las cenizas del quemadero se recogieron algunos fragmentos de pequeños platos. Estos platos tenían 0.085 de diámetro y estaban pintados en su interior de un círculo central de varias líneas.

No 21. 30-3-1901. 20Vo L.3.

Como hemos podido comprobar Bonsor no es muy explícito en sus descripciones debido, quizá, a la regularidad de los hallazgos omitiendo detalles. En este caso se limita a decir que halló una urna pintada al lado de un plato roto sin más especificaciones. Entre las cenizas, que no precisa donde se hallaban, localizó una fíbula con una cuenta de oro enfilada, un engaste de anillo móvil grabado y un pequeño vaso de cerámica, que dibuja, de tamaño y forma semejantes a los de un alabastrón, según sus indicaciones. 
No 22. Sin fecha (1901). 20 L.3.

Bonsor relata muy brevemente el hallazgo de un quemadero que tenía en el centro del mismo el hoyo de deposición con un vaso que dibuja el perfil, de cerámica marrón. Es un vaso de grandes dimensiones de boca ancha y con dos asas que parten del borde descansando sobre el hombro, de cuerpo ovoide con pie estrecho marcado, que resulta una forma atípica en la necrópolis. Los huesos incinerados se hallaban reunidos cerca de éste y entre éstos se halló una punta de lanza de hierro.

Sobre los hallazgos de puntas de lanza en la necrópolis observa que han sido intencionadamente deformadas tanto las de hierro como las de bronce.

No 23. 19-4-1901. 21Vo L.3.

Bonsor describe por referencia de su operario Rafael Pérez Barrera que ha descubierto dos quemaderos con urnas conteniendo los huesos incinerados cada una pero no especifica su lugar de deposición ni describe los quemaderos. Unicamente señala que estos quemaderos se encontraban superpuestos pero con orientaciones diferentes (ver enterramientos $n^{\circ} 2$ y 3 ).

Por otra parte hemos de señalar que este es el último enterramiento descrito de la campaña realizada entre finales de 1900 y abril de 1901, que es la campaña más continuada de todas las realizadas por Jorge Bonsor en la Cruz del Negro.

No 24. 1-2-1902. 24 L.3.

En el primer enterramiento descrito de esta campaña Bonsor dice que su operario halló a $1.50 \mathrm{~m}$ de profundidad una superficie quemada con huesos humanos incinerados $\mathrm{y}$ algunos huesos de pájaros no quemados. Entre los restos se recogió una varilla de hierro de aproximadamente $20 \mathrm{~cm}$ de largo que dibuja, rematada en ambos extremos por unas pequeñas bolas. También se recogieron cuatro objetos de hierro de los que dibuja dos de ellos que parecen una especie de abrazaderas con un pasador, cuyo uso es difícil de precisar. Junto con estos objetos se hallaron fragmentos de una lucerna fenicia de pasta gris y barniz rojo.

No 25. 18-3-1902. 26 L.3.

Bonsor describe este enterramiento en un dibujo en planta muy esquemático pero claro e ilustrativo como buen dibujante. En él se ven dos quemaderos de sección escalonada con una inhumación depositada entre ellos. Sin embargo en el castillo de Mairena existe el dibujo correspondiente a esta tumba, que también figura entre los publicados por L. Monteagudo (1953, fig. 2). En el dibujo conservado en la colección Bonsor se aprecian algunos detalles distintos del boceto de la presente documentación. En primer lugar se añade el dibujo en sección del enterramiento, además de la planta. Tanto en uno como en otro, el quemadero situado a la izquierda de la inhumación no posee el canalillo central como se dibuja en la documentación, presentando una fosa simple de escasa profundidad y planta rectangular que queda incompleto en el dibujo por uno de sus lados. El segundo quemadero es de planta rectangular y sección escalonada. Entre ambos, como hemos dicho se localizó una inhumación que, según Bonsor anota, se encontraba en posición violenta. A los pies de la inhumación, junto a la esquina N.E. del segundo quemadero, se depositó una urna globular. La boca de ésta se encontraba a nivel del suelo del emplazamiento del quemadero. Contenía un broche de cinturón. 
No 26. 19-3-1902. 26 L.3.

Según las indicaciones del operario de Bonsor, se halló en un hoyo de deposición un gran vaso chardon que contenía los restos incinerados que según Bonsor constituye algo excepcional. Con la descripción de este enterramiento finaliza la campaña de 1902.

\section{No 27. 13-1-1903. 28 L.3.}

- Como en la unidad de enterramiento no25 Bonsor describe ésta en un dibujo en planta y publicado por Monteagudo (1953, fig. 2). Se trata de un hoyo de deposición de planta circular de un metro de diámetro con un enterramiento doble y una inhumación infantil asociada. Por una parte se observa una urna globular y un vaso chardon separados por una laja de piedra. La urna contenía los restos calcinados y como ajuar una cuenta. El otro enterramiento lo constituye una vasija grande sirviendo de urna con los huesos y junto a ella un vaso chardon. Asociado a éste se halló en el borde del hoyo de deposición la inhumación infantil.

No 28. 26-2 1903. 3. L.5.

Se describe el hallazgo de una urna que según Bonsor es del tipo de las globulares aunque sensiblemente diferente. Esta contenía los huesos humanos incinerados, un alabastrón y un mango de cuchillo. Al lado de la urna se halló depositado un cuenco y dos o tres copas que dibuja. Así mismo, alrededor de la urna y junto a estas copas se recogió una punta de lanza de enmangue tubular y nervadura central, incompleta, y el talón.

No 29. 19-5-1903. 11 L.5.

El hoyo de deposición se hallaba en el medio del quemadero. En éste introducida entre los restos de la cremación localizó una copa, con pie y cuerpo esférico, y un plato encima a modo de tapadera. La copa contenía los huesos humanos calcinados y un escarabeo de pasta con un grabado de estilo egiptizante que dibuja, además de un objeto cuadrado en hueso, grabado con varios cuadros concéntricos.

En el quemadero, que no se describe, se hallaron fragmentos afectados por el fuego de broche de cinturón y fibula.

Este constituye el último enterramiento descrito correspondiente a la campaña de 1903.

No 30. 30-5-1904. 26Vo L.5.

Se describe en un dibujo muy esquemático en el que se ve un hoyo de deposición de planta circular lleno de carbón. Introducido en éste un vaso chardon roto y dos platos superpuestos que cubrían los huesos incinerados. Entre éstos se hallaron un cuchillo de hierro y una fíbula de doble resorte.

No 31. 17-12-1904. 32 L.5., 32Vo L.5.

Descrito en un dibujo en sección y en planta muy preciso. Se observa un hoyo de deposición de $0.50 \mathrm{~m}$ de diámetro y $0.40 \mathrm{~m}$ de profundidad, lleno de carbón e introducida en éste una urna globular que contenía los huesos incinerados. La boca de la urna se halló a $0.60 \mathrm{~m}$ del nivel superficial. Junto al hoyo de deposición se halló una inhumación infantil que según nos dice Bonsor en sus anotaciones le calcula, por los dientes recogidos, una edad entre los seis y ocho años. 
En el dibujo de este enterramiento publicado por Monteagudo, (1953, fig. 3) se observa que Bonsor añade un nivel más que lo reflejado en la documentación y es precisamente el que sella el enterramiento. El nivel, que se corresponde perfectamente con lo registrado en las recientes excavaciones, actúa como cerramiento de las tumbas y es de naturaleza muy semejante al tapial.

\section{No 32. 18-12-1904. 32Vo L.5.}

En esta ocasión se describe, en un dibujo en sección y en planta un quemadero de planta rectangular con el hoyo de deposición en el centro del quemadero albergando un vaso chardon y una urna globular. En el dibujo en sección se ve que en el hoyo de deposición están ambos vasos y acolmatado de carbón. La urna contiene los restos incinerados y el vaso chardon un plato.

\section{No 33. 14-1-1905. 33 L.5.}

En un dibujo en planta se ve un quemadero de planta rectangular con el hoyo de deposición en el centro del quemadero albergando una urna globular $\mathrm{y}$ un vaso chardon separados por una laja de piedra y una inhumación infantil asociada. Bonsor designa con letras cada uno de los elementos con las anotaciones siguientes:

A.- Esqueleto de niño, "víctima funeraria sacrificada en el último momento antes de recubrirlo todo con tierra".

B.- Fosa circular, cavada en el centro del emplazamiento del quemadero y en el cual se hallaban la urna y el vaso chardon.

C.- Vaso chardon cubierto por una fuente.

D.- Urna pintada de bandas rojas y líneas negras que contenía los huesos humanos incinerados y una cuenta de ágata.

E.- Laja de piedra que separa la urna del vaso chardon.

Este enterramiento fue publicado también por Monteagudo(1953, fig. 4). Añade Bonsor que debajo del cráneo del niño fue hallada la mandíbula del incinerado, "lo que indica que el cuerpo fue depositado en la pira con la cabeza orientada al Sur".

\section{No 34. 24-1-1905. 33Vo L.5.}

Otro caso similar al anterior con una inhumación asociada. Este enterramiento se encuentra también entre los recogidos por Monteagudo (1953, fig. 6). Se ve un hoyo de deposición lleno de carbón e introducida una urna globular que contenía la incineración. Próximo y junto a éste se halló una inhumación de un individuo adulto con orientación S.O. N.E. Bonsor nos dice que se trata de una mujer arrojada al suelo boca abajo y con los dedos de la mano derecha en la boca. No se especifica nada sobre el quemadero.

No35. 29-1-1905. 35Vo L.5.

En el dibujo, también publicado por Monteagudo, (1953, fig. 2) se ve un hoyo de deposición de planta circular que alberga una urna globular, una fíbula anular hispánica y una inhumación infantil. En sus anotaciones nos dice que fue hallado un esqueleto enterrado entre los restos del quemadero en posición anómala o forzada, por lo que piensa que haya sido arrojado al hoyo, dado que los grandes huesos están descoyuntados y yacen sobre el pecho y el cráneo además, se encontraba entre los dos fémures. Por otra parte indica que en el quemadero recogieron 
una fíbula anular, en buen estado. Según este último dato, tenemos que suponer que el hoyo de deposición se hallaba en el interior del quemadero por la proximidad de la fíbula a la urna. Esta última contenía un pendiente de oro.

No 36. sin fecha(1905) 35 L.5.

No tenemos la seguridad de que se trata de un enterramiento. Más bien pensamos que hace un dibujo del enterramiento tipo del yacimiento, con cierto aire artístico, al añadir el paisaje que existía cuando realizó las excavaciones, es decir, una síntesis de lo observado en los enterramientos de la necrópolis (fig. 1). Y así lo expresa en la descripción detallada de los diversos niveles que componen los enterramientos que describe así:

A. Plataforma de tierra apisonada cubriendo la sepultura.

B. Fosa circular, cavada en el centro o al lado del quemadero, conteniendo una urna y un vaso chardon introducidos en las cenizas del quemadero.

C. Esqueleto de nin̄o

D. Montículo de tierra.

E. Tierra vegetal.

A continuación describimos dos tipos de quemaderos recogidos por Bonsor en la documentación que no presentaron incineraciones asociadas:

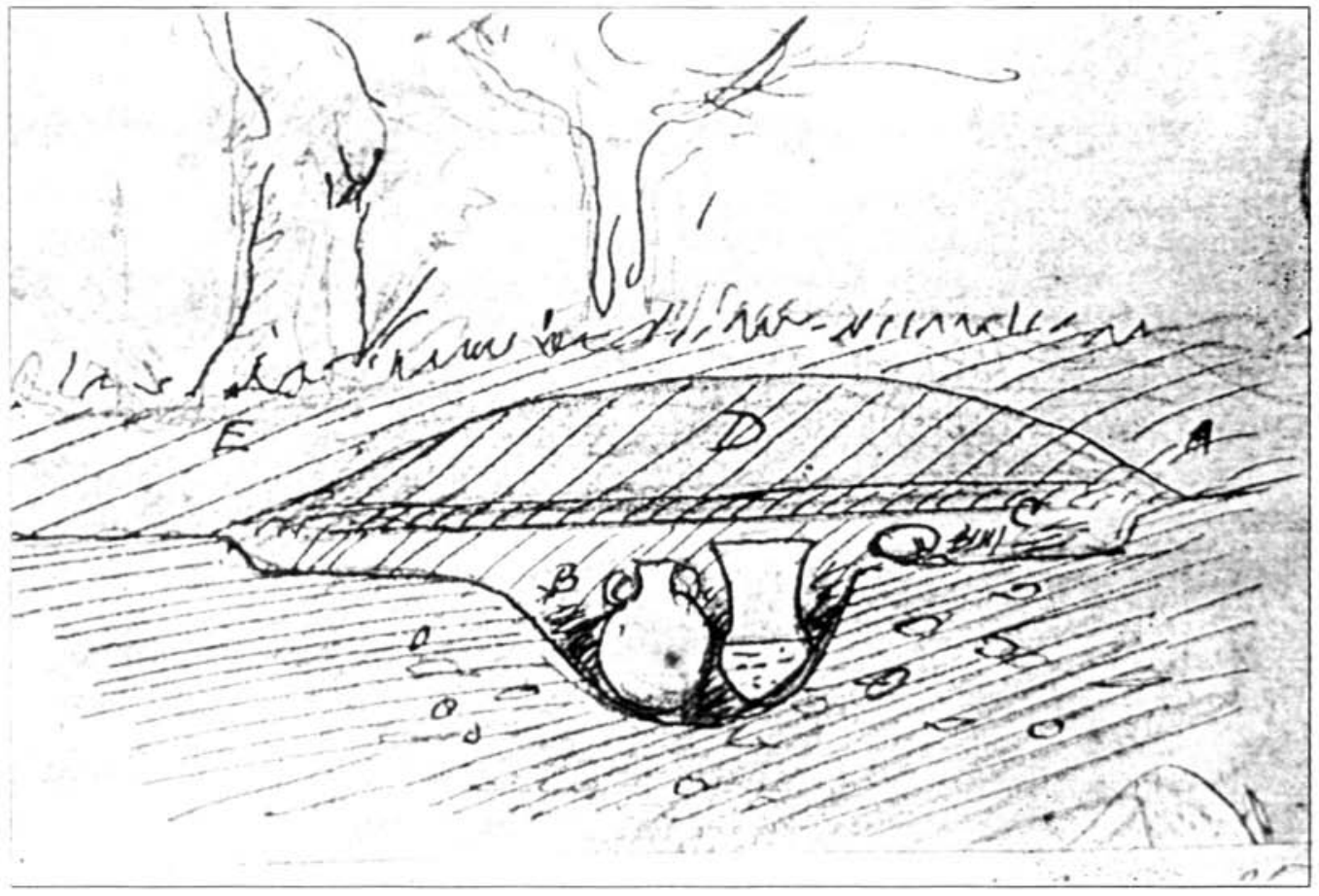

Figura 1: Cruz del Negro. Reconstrucción modélica de los enterramientos, según Bonsor, 1905, (p.35 L.5) 
No 1. 3-2-1903. 1 L.5.

Se trata de una fosa de cremación simple de sección rectangular con las esquinas redondeadas con orientación N.E. S.O. de $1.76 \mathrm{~m}$ de largo por 0.35 de ancho y 0.35 de profundidad. Según las anotaciones el paquete de tierra que cubría a éste tenía $0.60 \mathrm{~m}$ de potencia. Las paredes de la fosa estaban revocadas de un barro grisáceo y contenía restos de carbón de madera. Hacia la mitad de la fosa se halló un anillo de plata.

No 2. 2-3-1903. 4 L.5.

Este se encuentra entre los publicados por Monteagudo (1953, fig. 5). Se trata de una fosa de sección rectangular escalonada, es decir con canalillo central. Sus dimensiones son $1.37 \mathrm{~m}$. de largo por 1.10 de ancho, el canalillo central $1.10 \mathrm{~m}$ de largo por 0.20 de ancho y 0.18 de profundidad. Su orientación como en la mayoría de los casos es S.O. N.E. Halló fragmentos de marfil y restos de bronce afectados por el fuego entre las cenizas. En el extremo S.O. y junto a la pared se halló una lucerna fenicia.

\section{RITUAL Y TIPOLOGIA DE LAS TUMBAS}

El ritual generalmente empleado consiste en la incineración en urna cineraria. Ahora bien, de los hallazgos efectuados y de lo descrito por Bonsor se deduce que el cuerpo del difunto era incinerado en la pira funeraria y los restos calcinados con sus objetos de uso personal eran depositados en una urna. Esta, junto con los restos de la pira eran depositados en un hoyo y acompanados, aunque no siempre de objetos de ofrendas. El hoyo que adoptaba normalmente planta circular, se practicaba próximo a la fosa de cremación o en el interior de la misma. Así mismo, frecuentemente, los restos óseos incinerados no son recogidos en urna sino que son depositados en el suelo en el hoyo de deposición, normalmente en el interior del quemadero, cubiertos o no por cuencos a mano o probablemente recogidos en algún recipiente perecedero como cajas de madera. Tanto en un caso como en el otro las incineraciones pueden ir acompañadas de inhumaciones de adultos o infantiles.

Según la conjugación de estos elementos, hemos establecido las siguientes variantes de los enterramientos descritos por Jorge Bonsor:

A. El hoyo de deposición se encuentra dentro del quemadero.

B. El hoyo de deposición se encuentra fuera del quemadero, pero próximo a éste.

C. El hoyo de deposición se encuentra en el mismo quemadero pero tiene asociada una inhumación infantil.

D. El hoyo de deposición se encuentra próximo al quemadero pero tiene asociada una inhumación infantil o de adulto.

E. El hoyo de deposición se encuentra en el interior del quemadero y los restos óseos incinerados no están contenidos en urna.

$\mathrm{F}$. El hoyo de deposición se encuentra próximo al quemadero pero los restos incinerados no están recogidos en la urna.

G. El hoyo de deposición se encuentra en el interior del quemadero pero en este caso el hoyo es rectangular.

Respecto a las piras funerarias, muy abundantes en la necrópolis, son fosas de escasa profundidad excavadas en el nivel base de la necrópolis y la mayor parte de las mismas presentan una orientación regular: S.O. N.E. presumiblemente a que la acción del viento posibilitara una com- 
bustión más completa. Las más sencillas consisten en una fosa simple de no más de medio metro de profundidad con las esquinas redondeadas. Otro tipo son aquellas que presentan un canalillo central que actuaría como tiro de la pira recibiendo así más oxigenación la combustión y en consecuencia sea más perfecta.

Por lo tanto se pueden distinguir dos tipos de piras funerarias empleadas en la necrópolis:

- Fosas de sección escalonada o canalillo central.

- Fosas de plata rectangular simple.

Bonsor no nos da apenas noticias de los sistemas de cubrición de las diversas unidades de enterramiento descritas a excepción de la $\mathrm{n}^{\circ} 36$. Sin embargo por lo que se ha observado en las recientes excavaciones realizadas coincide plenamente con lo descrito por el arqueólogo inglés. Una vez concluido el ritual se cubría todo el espacio con una capa de tierra arcillosa con nódulos de cal, que Bonsor describe como una tierra amarillenta y compacta. Según nos dice, por encima de ésta se levantaba un pequeño montículo de tierra como señalización del enterramiento. Este último nivel no ha sido posible detectarlo en los últimos trabajos debido a la agresión que sufrió el yacimiento con motivo del desmonte de los olivos y el posterior rebaje y aplanación del terreno (Gil de los Reyes y otros, en prensa).

Por otra parte tenemos la referencia del hallazgo de una estela o cipo (Bonsor, 1927, 292, fig. 4) que presenta en una de sus caras un recuadro con líneas verticales y horizontales pintadas en rojo, que se conserva en el castillo de Mairena del Alcor. Este no procede exactamente de la Cruz del Negro. Apareció, reutilizado, formando parte de la construcción de una especie de cámara a modo de cista en un túmulo de la necrópolis de la Cañada de las Cabras, muy próxima a la Cruz del Negro, que sin duda formaría parte de esta última. La estela o cipo, sin embargo, tiene mucha semejanza con algunas de las halladas en Mozia (Sicilia) y Nora (Cerdeña) (Bisi, fig. 97, láms. L, LIV; Forte, 1966, lám. LXXV, 1) uniéndonos a la opinión de F. Amores (1982, 112) quién advirtió la semejanza.

\section{LAS URNAS CINERARIAS Y LOS AJUARES}

En una necrópolis de incineración las urnas constituyen el elemento principal. Son varios los tipos de vasos que se han destinado a tal fin en la Cruz del Negro.

El tipo de urna más conocido de la Cruz del Negro, que tomó la denominación del yacimiento, es un ánfora de cuerpo globular con decoración pintada y cuello estrecho y cilíndrico que presenta en su parte central un resalte o moldura del que arrancan dos asas geminadas o bífidas que descansan sobre el hombro; lleva pie indicado y el fondo presenta un omphalos central (Aubet 1976-78,272 y 1986, 111). Es el tipo de vaso más utilizado en la necrópolis. Se ha detectado en varias necrópolis tartésicas tanto dentro del área nuclear como en la periferia de la misma y en el Noreste de Africa. Su escasa presencia en ambientes fenicios occidentales y los paralelos poco rigurosos en Oriente permite pensar que sea una producción de un taller fenicio carmonense o gaditano (Aubet, 1986, 111 y ss.).

Otro tipo de vaso utilizado como urna en la necrópolis, es un vaso de grandes proporciones fabricado a mano, de cuerpo ovoide y acabado grosero y largo cuello bruñido con carena y pie circular, claramente tartésico. Este aparece en varias necrópolis tartésicas como en Setefilla (Aubet, 1981a, 135 y 1981b, 219), Bencarrón (documentado en los diarios en excavación de Bonsor), la Joya (Garrido, 1978, 36), Medellín (Almagro Gorbea, 1977, 399) y en las Cumbres (Ruiz Mata, 1988, 44.) La forma es muy antigua en el Bajo Guadalquivir fechándose sus ejem- 
plares más remotos en la Colina de los Quemados en el siglo IX a.c. y perdurando durante siglos posteriores hasta el siglo VI a.c. por lo menos.

Aunque no se especifica en ningún caso concreto en la documentación pero si se constata su hallazgo, se utilizan como urnas cinerarias ánforas fenicias. Su utilización como urnas es bastante inusual en necrópolis tartésicas aunque se han registrado en la tumba 19 de la Joya (Garrido, 1978) y en Puig des Molins (G. Bellard, 1990, 139-140). Por último hemos de señalar que sólo en un caso $\left(n^{\circ} 29\right)$ se ha utilizado una copa como urna cineraria. Desgraciadamente el dibujo de Bonsor de esta pieza no nos permite identificar la misma.

Respecto a los ajuares estos se distribuyen tanto en el interior de la urna como alrededor de ella. Estos no suelen contener más de un elemento aunque no se puede especificar una regularidad en cuanto a los mismos (ver Tabla)(2). Sólo tenemos un caso $\left(n^{\circ} 1\right)$ en el que el ajuar se compone de varios elementos.

Los materiales que acompañan a las urnas son, en la mayoría de los casos, vasos chardon o platos y en un caso una caja de marfil $\left(n^{\circ} 8\right)$. Además de éstos se conocen cerámicas a mano con motivos geométricos pintados (Aubet, 1982; Jiménez, 1986). Aunque no se mencionan en la documentación, se conservan a la Colección Bonsor un quema perfumes, un cuello de oinochoe de boca de seta, fragmentos de platos de barniz rojo y algunos ejemplares de cerámicas de retícula bruñida (Carriazo, 1974, fig. 63; López Roa, 1977, 345). Las lucernas, sin embargo, nunca son depositadas en los hoyos de deposición sino en los quemaderos y corresponden a prototipos fenicios con uno y dos mecheros.

Los ajuares metálicos, cuando los hay, consisten en broches de cinturón, fíbulas, pulseras de bronce con botones terminales, varillas de bronce rematadas con bolas, cuchillos afalcatados de hierro y puntas de lanza tanto de hierro como de bronce con sus talones. Quizá los elementos más sorprendentes de los ajuares sean los peines y objetos de marfil grabados, hallazgos que por ahora sólo se han producido principalmente en las necrópolis tartésicas de los Alcores (Aubet, $1979,6)$. Por último hay que añadir la presencia de escarabeos y alabastrones de pequeño tamaño. Los objetos de joyería son muy escasos tanto en oro como en plata del que solamente conocemos el hallazgo de un anillo en el quemadero $n^{\circ} 2$.

\section{ALGUNAS CONSIDERACIONES EN TORNO AL RITUAL FUNERARIO}

Las necrópolis de incineración han sido detectadas en Andalucía Occidental por lo menos durante el siglo VIII a.c. Aún no está suficientemente explicado el vacío existente en cuanto al ritual funerario empleado en esta zona antes de esta fecha a excepción de las estelas funerarias tartésicas, que se hallan descontextualizadas y por tanto de cronología imprecisa. No vamos a entrar en la cuestión sobre la adopción del rito de la incineración, con todo lo que ello supone en el Bajo Guadalquivir o mejor dicho en lo que se viene designando como área nuclear tartésica. Por ahora los únicos enterramientos conocidos que adoptan este rito antes de la llegada de los colonos orientales son los hallados en el túmulo I de la necrópolis de las Cumbres (Pto. Sta. María, Cádiz) que se fecha a lo largo del siglo VIII a.c. (Ruiz Mata, 1988, 47).

La necrópolis de la Cruz del Negro se viene fechando a través del estudio de los materiales, fundamentalmente de importación, a lo largo de los siglos VII-VI a.c. y se ha relacionado por el

(2) Las claves de lectura al final de la tabla. p. 115 
ritual funerario practicado con las necrópolis de los Alcores (que es la zona de mayor concentración de necrópolis de este tipo), Setefilla, La Joya, Medellín, Frigiliana, Rachgoun, Mogador (Aubet, 1986, 116-121) y las recientemente conocidas de las Cumbres y Puig des Molins. Sin embargo ciertas características las diferencian de éstas. En primer lugar no se trata de una necrópolis tumular por lo que tendría sus paralelos más cercanos con Frigiliana, Puig des Molins, Rachgoun y Mogador. Ahora bien, las excavaciones de éstas no han presentado la existencia de piras funerarias en número tan grande como en la Cruz del Negro. En Huelva, en la necrópolis de la Joya se detectaron la presencia de quemaderos, concretamente en la tumba 12, en que el hoyo de deposición se encontraba en medio de la fosa de cremación como ocurre en la Cruz del Negro (Garrido, 1978, 24-25). En Cádiz, en fechas más tardías (siglo VI a.c.) se han registrado la presencia de quemaderos pero en que los restos no han sido depositados en urnas (Perdigones, 1985, 53-54).

En la Cruz del Negro, como hemos descrito anteriormente, el ritual empleado, al igual que en las necrópolis citadas, es el de incinerar al individuo y posteriormente depositar sus restos en urna o no, en un hoyo de deposición. Según comprobamos en la documentación la variante más utilizada es practicar el hoyo de deposición en el centro del quemadero, así como próximo a la fosa de cremación, una vez realizada la incineración. También puede estar aislado sin asociación clara a la pira funeraria.

Por otra parte, poco podemos entrever en la documentación sobre la disposición del individuo en la pira, la preparación de la misma, la combustión de los cuerpos o la recogida de los huesos, aspectos todos ellos que quedarán esclarecidos por los datos que arrojen las recientes excavaciones practicadas. Sin embargo sobre este último aspecto Bonsor nos dice que el fuego de la pira era apagado antes de la consumación completa con algún líquido o tierra, para posteriormente proceder a la recogida de los huesos bien por tamizado o con pinzas de entre los restos de la pira. Es preciso recordar que la mayor parte de las fosas de cremación que constituían las piras funerarias poseen una orientación regular (S.O.N.E.). Las fosas de cremación de sección escalonada se han registrado en Cádiz y Puig des Molins y parecen corresponder a momentos más tardíos (siglo VI a.c.).

Según la documentación poco podemos precisar acerca de la frecuencia con que eran utilizadas las fosas de cremación. En las excavaciones recientes, por ejemplo, se han contabilizado el doble de hoyos de deposición, respecto a las piras, lo cual indica que, al menos, algunas de ellas fueron utilizadas en más de una ocasión.

Los hoyos de deposición albergaban además de la urna, los restos de la pira funeraria una vez recogidos los huesos y depositados en ésta junto con objetos personales (que no suelen ser más de un objeto o nada) de tal forma que quedaba introducida entre restos de madera carbonizada y cenizas en ocasiones acompañadas de objetos de ofrendas. Por lo tanto, las deposiciones siempre se realizaban en un hoyo simple practicado en la tierra de tendencia circular próximo a la pira o en la misma. Este hecho es homogéneo en todas las necrópolis tartésicas conocidas. Sin embargo los huesos pueden estar contenidos en urnas o depositados directamente en el hoyo de deposición, bien en un hueco horadado en el mismo hoyo o cubiertos por cuencos a mano, o bien alrededor del vaso de ofrendas, en caso que lo contengan, y suelen corresponder a vasos chardon en la mayoría de los casos (Tabla 1). Este grupo de enterramientos nos parece el más interesante de la necrópolis en función del ajuar que los componen ya que no incluyen ningún objeto de importación fenicio, tan abundantes en el yacimiento, salvo el $\mathrm{n}^{\circ} 24$ al que se asocia una lucerna fenicia de barniz rojo. Los ajuares que acompañan son fundamentalmente broches 
de cinturón, fíbulas de doble resorte, puntas de laza de bronce y hierro, pulseras de bronce, varillas con remates florales y cuchillos afalcatados de hierro. Como elementos cerámicos suelen ir acompañados de vasos chardon a mano y un vaso a mano de tipología incierta ( $\left.\mathrm{n}^{\circ} 22\right)$. En este tipo de enterramientos el hoyo de deposición se encuentra en medio del quemadero o no se especifica (Tabla 1).

Las incineraciones depositadas en vasos chardon a mano tampoco contienen ajuares de importación siendo estos muy pobres. Según Bonsor su utilización como urna es algo excepcional. Aunque su presencia es muy frecuente suelen aparecer como vasos de ofrendas sobre todo en aquellos casos en que la urna es un ánfora globular o los huesos humanos no están recogidos en urna. Este hecho permite entrever la importancia de este vaso en el ritual empleado en la necrópolis.

La mayor parte de los enterramientos son los realizados en urna globular, de los que se han contabilizado 19 en la documentación, salvo excepciones de una copa ( $\left.n^{\circ} 29\right)$ y una urna atípica $\left(n^{\circ} 28\right)$. Como hemos señalado las urnas globulares a torno están acompañadas de vasos chardon en la mayoría de los casos, siendo los ajuares, cuando los contienen, peines de marfil, broches de cinturón, cuentas de ágata o vidrio, pequeños albastrones y pendientes de oro. Sólo en un caso $\left(n^{\circ} 21\right)$ el ajuar contenía más de un elemento. Estos vasos junto con las ánforas de saco en la Cruz del Negro siempre han sido utilizados como urnas cinerarias y en ningún caso como vasos de ofrendas. Además son los únicos que poseen elementos de importación en sus ajuares, salvo algunos casos, según los datos que se reflejan en la documentación.

Uno de los aspectos más interesantes observados en la necrópolis lo constituyen las inhumaciones. Estas como ya hemos advertido anteriormente siempre se encuentran asociadas a incineraciones y en ningún caso aparecen individualizadas. En la presente documentación se contabilizan un total de once inhumaciones, cinco de individuos adultos, que Bonsor indentificó por la anchura de la cadera como femeninos y seis infantiles, pero ninguna masculina.

Los individuos adultos femeninos son los que presentan más claramente, según su posición, el haber recibido una muerte violenta y ninguno de ellos presenta ajuar asociado, salvo el caso $\mathrm{n}^{\circ} 15$ que presentaba una lucerna fenicia y varios fragmentos de ánfora rotos y esparcidos por el cuerpo. Sin embargo el individuo presentaba con claridad, según Bonsor, el cráneo aplastado intencionadamente.

Distinta posición y carácter parece que poseen las inhumaciones infantiles. Todas ellas yacen siempre junto al hoyo de deposición y no presentan ajuar asociado a excepción del $\mathrm{n}^{\circ} 14$, que es el único que presenta el cráneo aplastado intencionadamente y se encuentra muy próximo a una inhumación femenina. En ningún caso las inhumaciones infantiles se hallan depositadas en fosas, sino directamente sobre el suelo y por supuesto asociadas a urnas con incineraciones.

No existe una regularidad en cuanto a las variantes que se adoptan en el rito de incineración y la asociación de las inhumaciones. Predominan aquellos casos en que la incineración está contenida en urnas globulares.

La interpretación de estas inhumaciones como sacrificios rituales es bastante controvertida.

En la necrópolis de la Joya, en la tumba 13, se descubrió una sepultura de inhumación que contenía dos individuos adultos en posición violenta, aunque no se especifica el sexo, y sin ajuar, que pueden relacionarse con sacrificios rituales (Garrido, 1978, 39-40). Sin embargo no están asociadas a incineraciones directamente.

El mismo Bonsor nos describió una serie de tumbas en la necrópolis de incineración bajo túmulo en el Acebuchal (Carmona) que designó como "los lapidados" al encontrarse estos con el cráneo aplastado por piedras. Se descubrieron por lo menos nueve enterramientos de este tipo 
fuera de los túmulos y algunas de ellas presentaban ajuares bastante ricos. Bonsor no dudó sobre la muerte violenta de estos individuos, pero pensó que se trataba de moribundos o enfermos que fueron depositados en las fosas, que parece que se hicieron a toda prisa, para posteriormente darles muerte (Bonsor, 1899, 94).

Por otra parte, en Rachgoun, necrópolis muy similar a la Cruz del Negro, y de la que se ha pensado que fuera un enclave tartésico en el Norte de Africa (Aubet, 1986, 115-116), se han hallado nueve sepulturas de inhumación infantiles. Se hallaban depositadas sobre el suelo de roca y preferentemente en un agujero natural con los cuerpos encogidos o tendidos aprovechando las sinuosidades de la roca y el cráneo se encontraba protegido por una piedra. En todos los casos eran individuos de no más de ocho años. No presentaban ajuar salvo en un caso que presentó una pulsera de bronce (Vuillemot, 1955, 11-12). Algunas de ellas se asocian a los hoyos de deposición que contienen las incineraciones como ocurre en la Cruz del Negro.

Por último añadir que en la necrópolis romana de Cádiz se han detectado la presencia de enterramientos infantiles que presentaban el cráneo fracturado por un golpe contundente, es decir habían sido sacrificados. Sus edades oscilan entre los dos y cinco años y estaban depositados en fosas (Corzo, 1989, 240-241).

En el caso de las inhumaciones infantiles no tenemos constancia clara de que se traten de sacrificios rituales pues no poseemos datos antropológicos de las incineraciones descritas que confirmen o avalen tal proposición. Sin embargo sólo aparecen en las necrópolis de la Cruz del Negro y Rachgoun. En el caso de los adultos creemos que está confirmada tal hipótesis.

\section{CONCLUSIONES}

Ante todo hemos de resaltar la importancia de la presente documentación de alto valor científico, dentro de sus limitaciones, ya que nos permite conocer el ritual funerario de la necrópolis del que no se poseían muchos datos, y en cualquier caso enriquecerlos. Son varios los aspectos que resaltamos. En primer lugar la presencia de una cantidad enorme de quemaderos que contrasta con las restantes necrópolis tartésicas del Bajo Guadalquivir que le convierten en un gran conjunto de urnas con las implicaciones que ello conlleva en el conocimiento de la sociedad tartésica. A ello habría que añadir la presencia de sacrificios rituales de difícil interpretación pero no por ello menos interesante. Sin embargo el dato más interesante lo constituye, a nuestro modo de ver, la presencia de varias tumbas que consideramos las más antiguas y quizá anteriores a los efectos de la presencia fenicia, que por otra parte se observa desde fechas bastante antiguas como lo corroboran algunos de sus materiales de importación demostrando que Carmona fue uno de los puntos principales de interés desde el primer momento de la colonización. Nos referimos a aquellos enterramientos en que los restos de la cremación no están contenidos en urnas y no presentan ajuares de importación, pero si importantes ajuares sobre todo de metal. Relacionamos éstos con los descubiertos en el túmulo I de las Cumbres que no presentan ningún ajuar de importación y que el Dr. Ruiz Mata, su excavador, considera anteriores a la colonización fenicia fechándolos en el siglo VIII a.c. Su ajuar al igual que los de la Cruz del Negro, aunque éstos son contenidos en urna, pero de raigambre local (sobre todo vasos chardon) son elementos de metal como broches de cinturón, fíbulas de doble resorte y cuchillos de hierro, cuando los hay (Ruiz Mata, 1988, 44). Pensamos que los de la Cruz del Negro corresponderían a este momento aunque la necrópolis presenta un desarrollo más intenso en su etapa orientalizante (VII-VI a.c.) como lo demuestran los estudios llevados a cabo de sus materiales. 


\section{BIBLIOGRAFIA}

Almagro Gorbea, M. 1977: El Bronce Final y el periodo orientalizante en Extremadura, Bibliotheca Praeshistórica Hispana, XVI, Madrid.

AMORES, Fernando, 1982: Carta Arqueológica de los Alcores (Sevilla), Sevilla.

ARribas, A. y WilKINS, J. 1969: "La necrópolis fenicia del cortijo de las Sombras (Frigiliana, Málaga)", Pyrenae, 5, pp. 185-193.

Aubet Semmler, M. E. 1976-78: “Le cerámica a torno de la Cruz del Negro (Carmona, Sevilla)", Ampurias, 38-40, pp. 267-287.

... 1979: "Marfiles fenicios del Bajo Guadalquivir I. Cruz del Negro", Studia Archeologica, 52, Valladolid, pp. 5-67.

... 1981 a: "La necrópolis de Setefilla (Lora del Río, Sevilla): Túmulo A", Programa de Investigaciones Protohistóricas, Barcelona, pp. 53-160.

... 1981 b: "La necrópolis de Setefilla (Lora del Río, Sevilla): Túmulo B", Programa de Investigaciones Protohistóricas, Barcelona, pp. 161-223.

... 1982: "Un vaso a mano con decoración pintada de los Alcores de Carmona", Trabajos de Prehistoria, 39, pp. 385-388.

... 1986: "Contactos culturales entre el Bajo Guadalquivir y el Noroeste de Africa durante los siglos VII y VI a.c. Atti del Congreso Internazionale di Amalfi, 5-8 diciembre 1983, Nápoles, pp. 109-144.

BiSI, A. M. 1967: La stelle puniche, Instituto di Studi del Vicino Oriente-Universitá degli Studi, Roma.

BONSOR, G., 1899: "Les colonies agricoles preromaines de la vallée du Bétis", Revue Archeologique, XXXV, París, pp. 1-143.

... 1927: "La veritable origine de Carmona et les decouvertes archeologiques des Alcores", Revue Archeologique, Paris, pp. 285-300.

... 1928: Early engraved ivories in the collection of the Hispanic Society of America, New York.

CAÑAL, C. 1897: "Nuevas exploraciones de yacimientos prehistóricos en la provincia de Sevilla", Anales de la Sociedad Española de Historia Natural, XXV, pp. 351-375.

CERDEÑo, M. L. 1981: "Los broches de cinturón tartésicos”, Huelva Arqueológica, V, pp. 31-56.

Corzo, Ramón 1989: "Los sacrificios infantiles en Cádiz" en inhumaciones infantiles en el ámbito Mediterráneo español (siglos VII a.c. al II d.c.”, Cuadernos de Prehistoria y Arqueologia Castellonenses, 14, Castellón de la Plana, 1989, pp. 239-246.

Cuadrado, E. 1963: "Precedentes y prototipos de la fíbula anular Hispánica", Trabajos de Prehistoria del Seminario de Historia primitiva del Hombre, VII, Madrid, pp. 8-61.

Cuadrado, E. y Brito, M. 1970: "Broches tartésicos de cinturón de doble gancho", XI Congreso Nacional de Arqueologia, Mérida, 1968, Zaragoza, pp. 494-514.

FORTE, M., 1966: "Mozia II", Studi Semitici, 19, Roma.

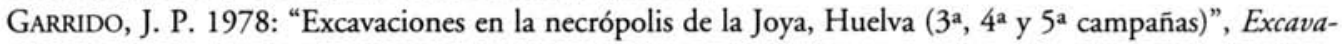
ciones Arqueológicas de España, 71, Madrid.

Gil DE los ReYes, M., PUYA, M., MaIer, J. y otros (en prensa) "Informe preliminar sobre el resultado de la excavación de emergencia de la necrópolis tartésica de la Cruz del Negro (Carmona, Sevilla)".

Gomez Bellard, C., 1990: "La colonización fenicia de la isla de Ibiza", Excavaciones Arqueológicas de España, 157, Madrid.

JIMENEZ BARRIENTOS, J. C. 1986: “Un vaso a mano con decoración pintada procedente de la Cruz del Negro (Carmona, Sevilla)”, Habis, 17, Sevilla, pp. 477-489. 
LOPEz ROA, C. 1977: “La cerámica con decoración bruñida en el Suroeste Peninsular”, Trabajos de Prehistoria, 34, Madrid, pp. 341-369.

Mata Carriazo, J. de, 1974: "Protohistoria de Sevilla", Sevilla.

Monteagudo, L. 1953: "Album gráfico de Carmona por G. Bonsor”, Archivo Español de Arqueologia, XXVI, Madrid, pp. 350-370.

Perdigones, L., Blanco, F., Muñoz, V., 1985: "Excavaciones de urgencia en un solar de la calle ciudad de Santander esquina Brunete (Cádiz) en 1985”, Anuario Arqueológico de Andalucia, III, Sevilla. pp. 53-57.

Remesal, J., 1977: “Cerámicas orientalizantes andaluzas”, Archivo Español de Arqueologia, XLVIII, Madrid, pp. 3-21.

Ruiz Delgado, M. M. 1986a: “Las necrópolis tartésicas: prestigio, poder y jerarquías”, Los fenicios en la Peninsula Ibérica, Barcelona, pp. 247-286.

... 1986 b: "La fíbula de doble resorte en Andalucía: I. Tipos y cronología", Habis, 17, Sevilla, pp. 491514.

Ruiz Mata, D. y Perez C., 1988: "La necrópolis tumular de las Cumbres: el túmulo 1. Puerto de Santa María, Cádiz”, Revista de Arqueologia, 87, Madrid, pp. 38-47.

SтоRCH, J. J., 1989: "La fibula en la Hispania antigua: las fibulas protohistóricas del Suroeste peninsular", Madrid.

VUillemot, G., 1955: "La necropole punique du phare dans l'ille Rachgoun (Oran)", Lybica, III, pp. 662. 


\section{CRUZ DEL NEGRO (CARMONA, SEVILLA)}

\begin{tabular}{|c|c|c|c|c|c|c|c|}
\hline U.E. & URNA & A.I.U. & A.E.U. & QUE. & M.QUE & INH. & OBS. \\
\hline No 1 & $\begin{array}{l}\text { Globular } \\
\text { a torno }\end{array}$ & $\begin{array}{l}\text { objetos } \\
\text { de marfil } \\
\text { grabados } \\
\text { y quema- } \\
\text { dos }\end{array}$ & $\begin{array}{l}\text { Un vaso } \\
\text { chardon } \\
y \text { un plato }\end{array}$ & $\begin{array}{l}\text { Sección } \\
\text { escalonada }\end{array}$ & $\begin{array}{l}\text { Plato } \\
\text { negro con } \\
\text { pie. } \\
\text { Un plato en } \\
\text { una gran } \\
\text { fuente con } \\
\text { pie. Tres } \\
\text { lucernas de } \\
\text { un pico. } \\
\text { Una } \\
\text { lucerna de } \\
\text { dos picos. } \\
\text { Soporte. }\end{array}$ & & $\begin{array}{l}\text { Sin hoyo } \\
\text { de depo- } \\
\text { sición. }\end{array}$ \\
\hline No 2 & $\begin{array}{l}\text { Globular } \\
\text { a torno }\end{array}$ & & $\begin{array}{l}\text { Un vaso. } \\
\text { Un plato }\end{array}$ & $\begin{array}{l}\text { Sección } \\
\text { escalonada }\end{array}$ & $\begin{array}{l}\text { Objetos } \\
\text { de marfil } \\
\text { quemado } \\
\text { (mueble) }\end{array}$ & & $\begin{array}{l}\text { Tumba } \\
\text { super- } \\
\text { puesta }\end{array}$ \\
\hline No 3 & $\begin{array}{l}\text { Vaso } \\
\text { chardon }\end{array}$ & & Un plato & Simple & & $\begin{array}{l}\text { Un adulto } \\
\text { femenino } \\
\text { en la fosa } \\
\text { de } \\
\text { cremación }\end{array}$ & $\begin{array}{l}\text { Hoyo de } \\
\text { deposición } \\
\text { fuera del } \\
\text { quemadero }\end{array}$ \\
\hline № 4 & $\begin{array}{l}\text { En el hoyo } \\
\text { de deposi- } \\
\text { ción }\end{array}$ & & $\begin{array}{l}\text { Vaso } \\
\text { chardon }\end{array}$ & Simple & $\begin{array}{l}\text { Fragmento } \\
\text { urna } \\
\text { globular }\end{array}$ & $\begin{array}{l}\text { Un adulto } \\
\text { en fosa } \\
\text { de crema- } \\
\text { ción }\end{array}$ & $\begin{array}{l}\text { Hoyo de } \\
\text { deposición } \\
\text { fuera del } \\
\text { quemadero }\end{array}$ \\
\hline No 5 & $\begin{array}{l}\text { En una } \\
\text { pequeña } \\
\text { fosa }\end{array}$ & & & Simple & & & $\begin{array}{l}\text { Fosa } \\
\text { cuadran- } \\
\text { gular }\end{array}$ \\
\hline No 6 & $\begin{array}{l}\text { Vaso } \\
\text { chardon }\end{array}$ & Conchas & & $\begin{array}{l}\text { Sobre el } \\
\text { suelo }\end{array}$ & & $\begin{array}{l}\text { Cráneo } \\
\text { infantil }\end{array}$ & $\begin{array}{l}\text { Hoyo de } \\
\text { deposición } \\
\text { fuera del } \\
\text { quemadero }\end{array}$ \\
\hline
\end{tabular}




\begin{tabular}{|c|c|c|c|c|c|c|c|}
\hline U.E. & URNA & A.I.U. & A.E.U. & QUE. & M.QUE & INH. & OBS. \\
\hline No 7 & $\begin{array}{l}\text { Globular } \\
\text { a torno }\end{array}$ & $\begin{array}{l}\text { Pequeño } \\
\text { alabastrón }\end{array}$ & & $\begin{array}{l}\text { No se } \\
\text { especifica }\end{array}$ & & & \\
\hline No8 & $\begin{array}{l}\text { Globular } \\
\text { a torno }\end{array}$ & & & $\begin{array}{l}\text { No se } \\
\text { especifica }\end{array}$ & $\begin{array}{l}\text { Vaso } \\
\text { chardon } \\
\text { con } \\
\text { fragmentos } \\
\text { de marfil } \\
\text { en su } \\
\text { interior y } \\
\text { alrededor }\end{array}$ & & $\begin{array}{l}\text { Hoyo de } \\
\text { deposición } \\
\text { fuera del } \\
\text { quemadero }\end{array}$ \\
\hline № 9 & $\begin{array}{l}\text { Globular } \\
\text { a torno }\end{array}$ & $\begin{array}{l}\text { Broche de } \\
\text { cinturón }\end{array}$ & $\begin{array}{l}\text { Vaso } \\
\text { chardon } \\
\text { con un } \\
\text { plato } \\
\text { cubriéndold }\end{array}$ & $\begin{array}{l}\text { No se } \\
\text { especifica }\end{array}$ & & & \\
\hline № 10 & $\begin{array}{l}\text { En el suelo, } \\
\text { en el hoyo } \\
\text { de } \\
\text { deposición }\end{array}$ & $\begin{array}{l}\text { varillas de } \\
\text { bronce } \\
\text { con } \\
\text { remates } \\
\text { florales }\end{array}$ & & $\begin{array}{l}\text { No se } \\
\text { especifica }\end{array}$ & & & $\begin{array}{l}\text { Hoyo de } \\
\text { deposición } \\
\text { en el } \\
\text { interior } \\
\text { del } \\
\text { quemadero }\end{array}$ \\
\hline № 11 & $\begin{array}{l}\text { Vaso } \\
\text { chardon }\end{array}$ & $\begin{array}{l}\text { Broche de } \\
\text { cinturón }\end{array}$ & & $\begin{array}{l}\text { No se } \\
\text { especifica }\end{array}$ & & & \\
\hline № 12 & $\begin{array}{l}\text { Globular } \\
\text { a torno }\end{array}$ & & & $\begin{array}{l}\text { No se } \\
\text { especifica }\end{array}$ & & & \\
\hline № 13 & $\begin{array}{l}\text { En el suelo, } \\
\text { en el hoyo } \\
\text { de } \\
\text { deposición } \\
\text { cubiertos } \\
\text { por una } \\
\text { pátera a } \\
\text { mano }\end{array}$ & & $\begin{array}{l}\text { Vaso } \\
\text { chardon. } \\
\text { Fragmentos } \\
\text { de cerámica } \\
\text { a mano } \\
\text { con } \\
\text { incisiones }\end{array}$ & $\begin{array}{l}\text { No se } \\
\text { especifica }\end{array}$ & & & $\begin{array}{l}\text { Hoyo de } \\
\text { deposición } \\
\text { en el } \\
\text { interior } \\
\text { del } \\
\text { quemadero }\end{array}$ \\
\hline № 14 & $\begin{array}{l}\text { Vaso a } \\
\text { mano }\end{array}$ & $\begin{array}{l}\text { Anillo } \\
\text { de cobre }\end{array}$ & $\begin{array}{l}\text { Cuenta de } \\
\text { vidrio }\end{array}$ & $\begin{array}{l}\text { No se } \\
\text { especifica }\end{array}$ & & $\begin{array}{l}\text { Infantil, } \\
\text { cráneo } \\
\text { aplastado }\end{array}$ & \\
\hline
\end{tabular}




\begin{tabular}{|c|c|c|c|c|c|c|c|}
\hline U.E. & URNA & A.I.U. & A.E.U. & QUE. & M.QUE & INH. & OBS. \\
\hline № 15 & $\begin{array}{l}\text { Globular } \\
\text { a torno }\end{array}$ & & $\begin{array}{l}\text { Lucerna } \\
\text { de un pico. } \\
\text { Fragmentos } \\
\text { de ánfora. } \\
\text { Lápiz de } \\
\text { ocre } \\
\text { amarillo }\end{array}$ & $\begin{array}{l}\text { No se } \\
\text { especifica }\end{array}$ & & $\begin{array}{l}\text { Adulto } \\
\text { femenino, } \\
\text { cráneo } \\
\text { aplastado }\end{array}$ & \\
\hline № 16 & $\begin{array}{l}\text { Dos } \\
\text { globulares } \\
\text { a torno }\end{array}$ & $\begin{array}{l}\text { Dos } \\
\text { broches } \\
\text { de cinturón }\end{array}$ & $\begin{array}{l}\text { Vaso } \\
\text { chardon }\end{array}$ & $\begin{array}{l}\text { No se } \\
\text { especifica }\end{array}$ & & & $\begin{array}{l}\text { Enterra- } \\
\text { miento } \\
\text { doble }\end{array}$ \\
\hline No 17 & $\begin{array}{l}\text { En el suelo } \\
\text { en el hoyo } \\
\text { de } \\
\text { deposición } \\
\text { cubiertos } \\
\text { por un } \\
\text { plato }\end{array}$ & $\begin{array}{l}\text { Broche de } \\
\text { cinturón }\end{array}$ & $\begin{array}{l}\text { Vaso } \\
\text { chardon }\end{array}$ & $\begin{array}{l}\text { No se } \\
\text { especifica }\end{array}$ & & & \\
\hline No 18 & $\begin{array}{l}\text { En el suelo, } \\
\text { en el hoyo } \\
\text { de } \\
\text { deposición }\end{array}$ & $\begin{array}{l}\text { Fíbula de } \\
\text { doble } \\
\text { resorte. } \\
\text { Punta de } \\
\text { lanza y su } \\
\text { talón. } \\
\text { Cuchillo de } \\
\text { hierro. } \\
\text { Pulsera de } \\
\text { bronce }\end{array}$ & $\begin{array}{l}\text { Vaso } \\
\text { chardon }\end{array}$ & $\begin{array}{l}\text { No se } \\
\text { especifica }\end{array}$ & & & \\
\hline № 19 & $\begin{array}{l}\text { Globular } \\
\text { a torno }\end{array}$ & $\begin{array}{l}\text { Peine de } \\
\text { marfil } \\
\text { grabado }\end{array}$ & $\begin{array}{l}\text { Vaso } \\
\text { chardon }\end{array}$ & $\begin{array}{l}\text { No se } \\
\text { especifica }\end{array}$ & & & \\
\hline № 20 & $\begin{array}{l}\text { En el suelo, } \\
\text { en el hoyo } \\
\text { de } \\
\text { deposición } \\
\text { cubiertos } \\
\text { por una } \\
\text { fuente }\end{array}$ & $\begin{array}{l}\text { Un } \\
\text { pequeño } \\
\text { anillo y } \\
\text { fragmentos } \\
\text { de cobre }\end{array}$ & $\begin{array}{l}\text { Vaso } \\
\text { chardon } \\
\text { cubierto } \\
\text { por una } \\
\text { gran } \\
\text { fuente con } \\
\text { platos en } \\
\text { su interior }\end{array}$ & $\begin{array}{l}\text { No se } \\
\text { especifica }\end{array}$ & $\begin{array}{l}\text { Pequeños } \\
\text { platos } \\
\text { pintados } \\
\text { con círculos } \\
\text { concéntricos }\end{array}$ & & \\
\hline
\end{tabular}




\begin{tabular}{|c|c|c|c|c|c|c|c|}
\hline U.E. & URNA & A.I.U. & A.E.U. & QUE. & M.QUE & INH. & OBS. \\
\hline No 21 & $\begin{array}{l}\text { Globular } \\
\text { a torno }\end{array}$ & $\begin{array}{l}\text { Pequeña } \\
\text { fibula con } \\
\text { una cuenta } \\
\text { de oro } \\
\text { enfilada. } \\
\text { Engaste de } \\
\text { anillo. } \\
\text { Alabastrón } \\
\text { de cerámica }\end{array}$ & Un plato & $\begin{array}{l}\text { No se } \\
\text { especifica }\end{array}$ & & & \\
\hline No 22 & $\begin{array}{l}\text { En el suelo, } \\
\text { en el hoyo } \\
\text { de } \\
\text { deposición }\end{array}$ & $\begin{array}{l}\text { Punta de } \\
\text { lanza de } \\
\text { hierro }\end{array}$ & $\begin{array}{l}\text { Cerámica } \\
\text { globular } \\
\text { con dos } \\
\text { asas a mano }\end{array}$ & $\begin{array}{l}\text { No se } \\
\text { especifica }\end{array}$ & & & $\begin{array}{l}\text { Hoyo de } \\
\text { deposición } \\
\text { en el } \\
\text { interior } \\
\text { del } \\
\text { quemadero }\end{array}$ \\
\hline No 23 & $\begin{array}{l}\text { Globular } \\
\text { a torno }\end{array}$ & & & $\begin{array}{l}\text { No se } \\
\text { especifica }\end{array}$ & & & $\begin{array}{l}\text { Quemade- } \\
\text { ros } \\
\text { superpues- } \\
\text { tos }\end{array}$ \\
\hline No 24 & En el suelo & $\begin{array}{l}\text { Varilla de } \\
\text { hierro. } \\
\text { Abrazaderas } \\
\text { de hierro. } \\
\text { Lucerna de } \\
\text { barniz rojo }\end{array}$ & $\begin{array}{l}\text { Huesos de } \\
\text { pájaro }\end{array}$ & Superficial & & & $\begin{array}{l}\text { Sin hoyo } \\
\text { de } \\
\text { deposición }\end{array}$ \\
\hline No 25 & $\begin{array}{l}\text { Globular } \\
\text { a torno }\end{array}$ & $\begin{array}{l}\text { Broche de } \\
\text { cinturón }\end{array}$ & & $\begin{array}{l}\text { Sección } \\
\text { escalonada }\end{array}$ & & $\begin{array}{l}\text { Un adulto } \\
\text { en posición } \\
\text { violenta }\end{array}$ & $\begin{array}{l}\text { Hoyo de } \\
\text { deposición } \\
\text { fuera del } \\
\text { quemadero }\end{array}$ \\
\hline No 26 & $\begin{array}{l}\text { Vaso } \\
\text { chardon }\end{array}$ & & & $\begin{array}{l}\text { No se } \\
\text { especifica }\end{array}$ & & & \\
\hline No 27 & $\begin{array}{l}\text { Globular } \\
\text { a torno. } \\
\text { Vasija a } \\
\text { mano }\end{array}$ & $\begin{array}{l}\text { Una } \\
\text { cuenta. }\end{array}$ & $\begin{array}{l}\text { Vaso } \\
\text { chardon. } \\
\text { Vaso } \\
\text { chardon }\end{array}$ & $\begin{array}{l}\text { No se } \\
\text { especifica }\end{array}$ & & Infantil & $\begin{array}{l}\text { Enterra- } \\
\text { miento } \\
\text { doble }\end{array}$ \\
\hline № 28 & $\begin{array}{l}\text { Urna } \\
\text { atípica }\end{array}$ & $\begin{array}{l}\text { Alabastrón. } \\
\text { Mango de } \\
\text { cuchillo }\end{array}$ & $\begin{array}{l}\text { Un cuenco. } \\
2 \text { ó } 3 \text { copas. } \\
\text { Punta de } \\
\text { lanza y su } \\
\text { talón de } \\
\text { bronce. }\end{array}$ & $\begin{array}{l}\text { No se } \\
\text { especifica }\end{array}$ & & & \\
\hline
\end{tabular}




\begin{tabular}{|c|c|c|c|c|c|c|c|}
\hline U.E. & URNA & A.I.U. & A.E.U. & QUE. & M.QUE & INH. & OBS. \\
\hline № 29 & $\begin{array}{l}\text { Copa con } \\
\text { pie }\end{array}$ & $\begin{array}{l}\text { Escarabeo. } \\
\text { Hueso } \\
\text { grabado. }\end{array}$ & & $\begin{array}{l}\text { No se } \\
\text { especifica }\end{array}$ & $\begin{array}{l}\text { Broche de } \\
\text { cinturón } \\
\text { Fíbula }\end{array}$ & & $\begin{array}{l}\text { Hoyo de } \\
\text { deposición } \\
\text { en el } \\
\text { interior } \\
\text { del } \\
\text { quemadero }\end{array}$ \\
\hline No 30 & $\begin{array}{l}\text { En el suelo, } \\
\text { dos platos } \\
\text { de cubierta }\end{array}$ & $\begin{array}{l}\text { Fíbula de } \\
\text { doble } \\
\text { resorte. } \\
\text { Cuchillo de } \\
\text { hierro }\end{array}$ & $\begin{array}{l}\text { Vaso } \\
\text { chardon }\end{array}$ & $\begin{array}{l}\text { No se } \\
\text { especifica }\end{array}$ & & & \\
\hline № 31 & $\begin{array}{l}\text { Globular } \\
\text { a torno }\end{array}$ & & & $\begin{array}{l}\text { No se } \\
\text { especifica }\end{array}$ & & Infantil & \\
\hline № 32 & $\begin{array}{l}\text { Globular } \\
\text { a torno }\end{array}$ & & $\begin{array}{l}\text { Vaso } \\
\text { chardon } \\
\text { con un } \\
\text { plato en su } \\
\text { interior }\end{array}$ & Simple & & & $\begin{array}{l}\text { Hoyo de } \\
\text { deposición } \\
\text { en el } \\
\text { interior } \\
\text { del } \\
\text { quemadero }\end{array}$ \\
\hline № 33 & $\begin{array}{l}\text { Globular } \\
\text { a torno }\end{array}$ & $\begin{array}{l}\text { Cuenta de } \\
\text { ágata }\end{array}$ & $\begin{array}{l}\text { Vaso } \\
\text { chardon }\end{array}$ & Simple & & Infantil & $\begin{array}{l}\text { Hoyo de } \\
\text { deposición } \\
\text { en el } \\
\text { interior } \\
\text { del } \\
\text { quemadero }\end{array}$ \\
\hline № 34 & $\begin{array}{l}\text { Globular } \\
\text { a torno }\end{array}$ & & & $\begin{array}{l}\text { No se } \\
\text { especifica }\end{array}$ & $\begin{array}{l}\text { Adulto } \\
\text { femenino }\end{array}$ & & \\
\hline № 35 & $\begin{array}{l}\text { Globular } \\
\text { a torno }\end{array}$ & $\begin{array}{l}\text { Pendiente } \\
\text { de oro }\end{array}$ & $\begin{array}{l}\text { Fíbula } \\
\text { anular }\end{array}$ & $\begin{array}{l}\text { No se } \\
\text { especifica }\end{array}$ & & Infantil & $\begin{array}{l}\text { Hoyo de } \\
\text { deposición } \\
\text { en el } \\
\text { interior } \\
\text { del } \\
\text { quemadero }\end{array}$ \\
\hline
\end{tabular}

Leyenda: U.E. Unidad de enterramiento.
A.I.U. Ajuar interior urna.
A.E.U. Ajuar exterior urna
QUE. Quemadero.
M.QUE. Materiales quemadero
INH. Inhumación
OBS. Observaciones 